\title{
Nd:YAG Laser Accidentally Hitting the Corneal Layers During Treatment of Posterior Capsule Opacification After Cataract Surgery and Its Postoperative Process
}

This article was published in the following Dove Press journal:

International Medical Case Reports Journal

\author{
Takeshi Teshigawara (D) ${ }^{1-3}$ \\ Akira Meguro $\mathbb{1}^{3}$ \\ Nobuhisa Mizuki ${ }^{3}$ \\ 'Yokosuka Chuoh Eye Clinic, Yokosuka, \\ Kanagawa, Japan; ${ }^{2}$ Tsurumi Chuoh Eye \\ Clinic, Yokohama, Tsurumi, Japan; \\ ${ }^{3}$ Department of Ophthalmology, \\ Yokohama City University School of \\ Medicine, Yokohama, Kanazawa, Japan
}

\begin{abstract}
Posterior capsule opacification (PCO) is the most common cause of deterioration of vision and contrast sensitivity and glare after cataract surgery. Neodymium $(\mathrm{Nd})$ : yttrium aluminum garnet (YAG) laser capsulotomy is an effective and standard procedure to treat these symptoms. The incidence rate of PCO requiring Nd:YAG laser treatment varies and depends on published studies, ranging from $2.2 \%$ to $10.0 \%$. Although Nd:YAG laser treatment is largely safe, it still has complications, such as transient increase of intraocular pressure, anterior uveitis, intraocular lenses pitting, cystoid macula edema, endophthalmitis, and retinal detachment. We encountered a rare complication related to Nd:YAG laser treatment, where the laser accidentally hits the cornea. This occurred because the PCO was mistaken for the corneal layers during the laser procedure. This report presents the 3-year post-treatment process, and the findings herein may help raise the awareness of the possibility of this rare complication and provide measures for its treatment.
\end{abstract}

Keywords: cornea, laser treatment, complication, PCO

\section{Introduction}

Posterior capsule opacification (PCO) is the most common complication after cataract surgery. ${ }^{1}$ With the advent of neodymium yttrium aluminum garnet (Nd-YAG) in the early 1980 s, PCO is readily treated. ${ }^{2}$ Nd:YAG is a laser with a wavelength of $1064 \mathrm{~nm}$ that causes photodisruption of the thickened posterior capsule. ${ }^{2}$ While Nd:YAG is widely accepted as a minimally invasive treatment for PCO, some complications were reported. ${ }^{3}$ Relatively common complications are an increase in intraocular pressure (IOP), intraocular lens pitting, decrease in endothelium cell density, and iritis. Relatively rare and sight-threatening complications include chronic endophthalmitis, cystoid macular edema, retinal detachment, and macular hemorrhage. ${ }^{3}$ However, we encountered a rare complication related to $\mathrm{Nd}: \mathrm{YAG}$ laser treatment, as the laser accidentally hit the cornea. This case report presents this very rare complication of $\mathrm{Nd}$ :YAG capsulotomy and its postoperative treatment course.

\section{Case Report}

Detailed information about this case report was given to the patient before he provided informed consent for the publication of this case report. This case study was approved by the Ethics Committee of the Yokosuka Chuo Eye Clinic.
Correspondence: Takeshi Teshigawara Yokosuka Chuoh Eye Clinic, 2-6 OdakiCho, Yokosuka, Kanagawa 238-0008, Japan

Tel +8I 46827400

Fax +8146827414 I

Email teshitake@gmail.com 
A 70-year-old man presented with blurred vision in both eyes. Based on the ophthalmic examination, he was diagnosed with cataract and underwent cataract surgery (phacoemulsification with intraocular lens [IOL] implantation) in both eyes. Cumulative dissipated energy (CDE) was 2.3 second in the right eye and 2.1 second in the left eye. No complications were found during and after the operations. On his last visit, the best-corrected visual acuity in both eyes were 20/20 without photopic phenomena such as haze and glare, and endothelial cell densities and corneal thickness checked by CellChek XL (Konan Medical, Hyogo, Japan) were 2502 cells $/ \mathrm{mm}$ and $545 \mu \mathrm{m}$ in the right eye, and $2494 \mathrm{cells} / \mathrm{mm}$ and $541 \mu \mathrm{m}$ in the left eye, respectively, at the central part of the cornea.

At 2.5 years after the operation, he revisited the clinic due to a gradual increase in haze and glare and a decrease in visual acuity in both eyes. On examination, his visual acuity in both eyes was found to be 20/30. PCO was revealed with the slit-lamp examination, but no other abnormality was found in both eyes. PCO was considered to be the cause of bilateral visual deterioration, and he was advised to undergo Nd:YAG laser treatment. After giving a detailed explanation about possible complications relevant to Nd:YAG laser treatment, the patient provided consent for treatment. Treatments were scheduled for the left eye, followed by the right eye.

Posterior capsulotomy in the left eye was performed with an Nd:YAG laser (Ultra Q Reflex-YAG, Ellex Medical, Australia) and Ocular Abraham Capsulotomy lens (Ocular Instruments, WA, USA). Single pulse mode $\mathrm{Nd}$ :YAG laser with an energy of $1.0 \mathrm{~mJ} /$ pulse was applied, and the posterior defocus was $0.50 \mathrm{~mm}$. Before the laser procedure, topical anesthesia with $0.4 \%$ oxybuprocaine eye drops (Benoxyl; Santen Pharmaceutical Co., Osaka, Japan) was administered after maximal dilatation of the pupil with $0.5 \%$ tropicamide and $0.5 \%$ phenylephrine hydrochloride (Mydrin-P, Santen Pharmaceutical, Osaka, Japan).

The patient was cooperative during the procedure. After 14 laser spots with a total laser energy of $14.0 \mathrm{~mJ}$ were delivered, the doctor realized that they had mistaken the corneal layers for the membranous posterior capsule. A slit-lamp examination revealed the laser spots in the stromal and endothelial cell layers and swollen stroma in the cornea (Figure 1A). The other part of the cornea was intact. The visual acuity was 20/60, and the IOP was 16 $\mathrm{mmHg}$ immediately after the procedure. Endothelial cell density was checked by CellChek XL (Konan Medical, Hyogo, Japan); however, because the cornea was swollen, the image was not clear enough to calculate the density. The patient was advised to use $0.1 \%$ betamethasone sodium phosphate eye drops (Rinderon, Shionogi Pharmaceutical, Osaka, Japan) six times a day.

The visual acuity and corneal condition did not improve on day 1 after the Nd:Yag procedure and remained the same at 1 week and 1 month after the procedure. Thus, $0.1 \%$ betamethasone sodium phosphate eye drops had been administered to decrease the swelling of the cornea (Figure 1B).

At 3 months after the operation, the patient's visual status had been improving. In line with the decrease in the swelling of the cornea, the visual acuity had improved to 20/30. As the corneal opaqueness decreased, the trace of the laser shot became visible with the slit-lamp examination (Figure 1C). Since the patient desired a second trial of Nd:YAG laser treatment, it was performed by a different doctor. The second trial was performed with the same devices, and single pulse mode Nd:YAG laser of an energy of $0.8 \mathrm{~mJ} /$ pulse was applied, with $0.50-\mathrm{mm}$ posterior defocus. Ten laser spots with a total laser energy of $8.0 \mathrm{~mJ}$ were used. No complication was observed during and after the procedure, and the visual acuity improved up to 20/20 on the following day (Figure 1D). Endothelial cell densities and corneal thickness were 2415 cells $/ \mathrm{mm}$ and $543 \mu \mathrm{m}$ at the central part of the cornea, respectively (Figure 2A). The result of a contrast sensitivity test (Contrast Glaretester, Takagi, Japan) was slightly lower than normal. Since then, no fluctuations in the results of ophthalmic examinations including slit-lamp examination, ie, visual acuity, IOP, and contrast sensitivity, apart from endothelial cell densities and visual acuity, had been observed.

At 1 year after the first laser trial, endothelial cell densities and corneal thickness were 2245 cells/mm and $552 \mu \mathrm{m}$, respectively (Figure 2B). However, these values changed into 908 cells $/ \mathrm{mm}$ and $575 \mu \mathrm{m}$ (Figure 2C), 837 cells $/ \mathrm{mm}$ and $586 \mu \mathrm{m}$ (Figure 2D), and $698 \mathrm{cells} / \mathrm{mm}$ and $592 \mu \mathrm{m}$ (Figure 2E) at 2, 2.5, and 3 years, respectively. On the other hand, the endothelial cell density and corneal thickness were 2404 cells $/ \mathrm{mm}$ and $581 \mu \mathrm{m}$ in the right eye at 3 years (Figure 2F). At 3 years, the corneal transparency was maintained based on the slit-lamp examination, and the patient had no complaint about the quality of vision. The patient was still being followed up.

\section{Discussion}

To the best of our knowledge, this is the first report where the physician accidentally shot the corneal layers with $\mathrm{Nd}$ : 

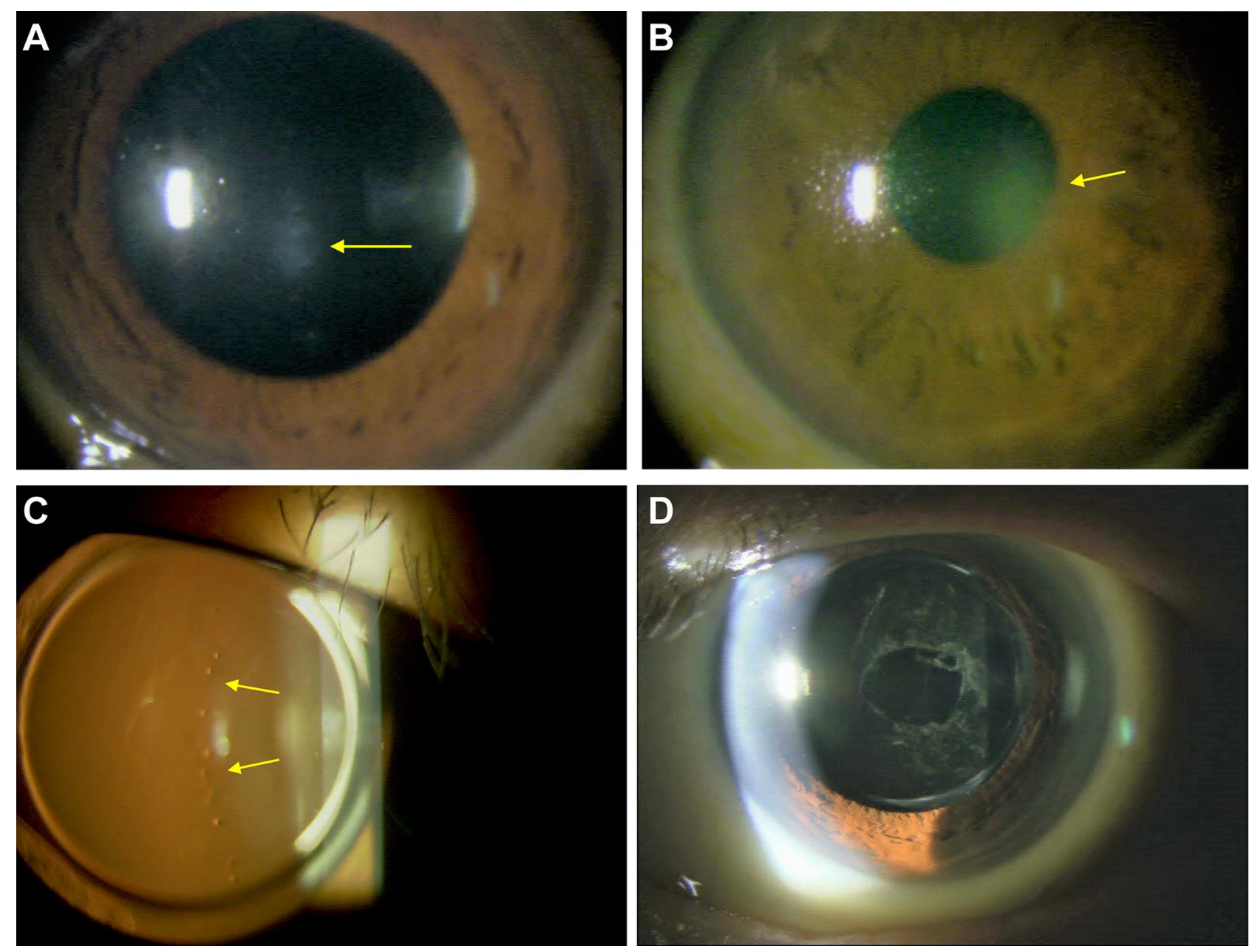

Figure I The cornea under Nd:YAG laser treatment. (A) The cornea immediately after the laser shot. Opaqueness caused by corneal edema (yellow arrow), and laser spots were observed. (B) The cornea I month after the laser shot. Opaqueness still maintained in the pupil area (yellow arrow). (C) The retro-illumination of the cornea 3 months after the operation. As the opaqueness disappeared, the trace of the laser spots became more distinctive (yellow arrows). (D) Nd:YAG laser treatment at 3 months after the first trial.
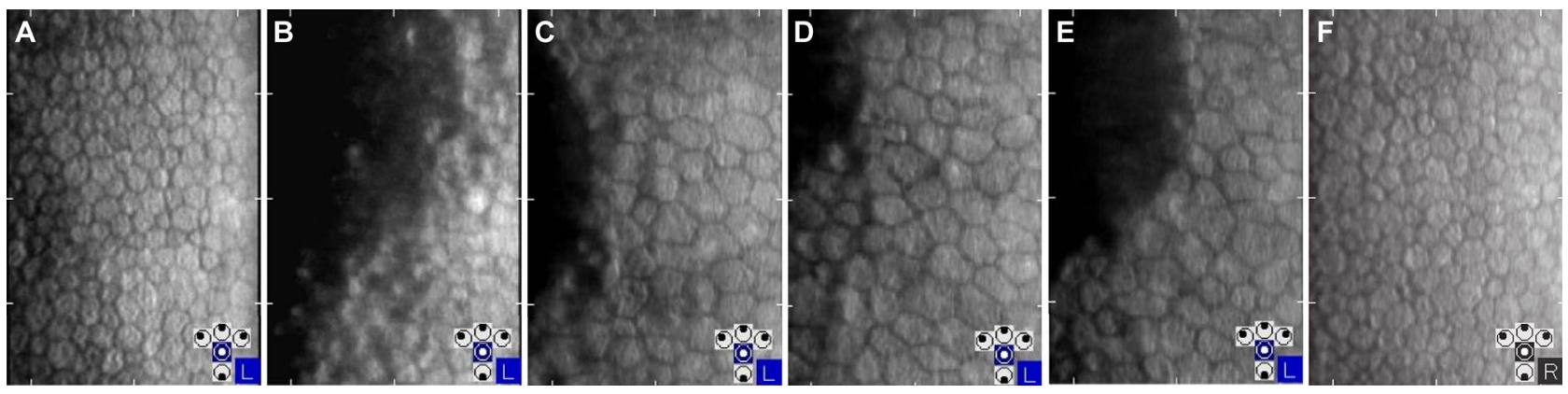

Figure 2 Endothelial cell densities. Endothelial cell densities at (A) 3 months, (B) I year, (C) 2 years, (D) 2.5 years, and (E) 3 years after the first laser trial. Endothelial cell densities in the fellow eye at 3 years (F).

YAG laser during treatment of PCO. This report presented the possibility of accidentally hitting the cornea with $\mathrm{Nd}$ : YAG laser during PCO treatment and its postoperative process.
The possibility of the requirement of Nd:YAG laser treatment after cataract surgery varies with different studies. Ton Van et al and Johansson et al reported the 3-year cumulative incidence of $\mathrm{PCO}$ requiring Nd:YAG laser 
capsulotomy, ie, $2.2 \%$ and $10.0 \%$, respectively. ${ }^{4,5}$ However, Baratz et al reported $6 \%$ at 1 year, which increased to $38 \%$ at 9 years. ${ }^{6}$

$\mathrm{Nd}$ :YAG laser treatment is a generally safe method to relieve the symptoms of $\mathrm{PCO}$, such as reduction in visual acuity, haze, and glare. However, Nd:YAG laser treatment has some complications, including transient rise in IOP, anterior uveitis, IOL pitting, cystoid macular edema, and retinal detachment. ${ }^{7}$ Although rare complications have also been published, ${ }^{8,9}$ there have been no previous reports about accidental injury of the corneal layers with Nd:Yag laser and the resultant postoperative course. The Nd:YAG laser causes photodisruption of the posterior capsule; therefore, the largest concern of a misplaced Nd:YAG laser shot in the corneal layers is the disruption of the corneal stromal layer and endothelial cells. While the disruption of the corneal stromal layer can induce wound healing response and cause tissue fibrosis, ${ }^{10}$ the disruption of endothelial cells can lead to irreversible corneal edema. Topical steroid works to eliminate macrophage and lymphocyte intervention during the wound healing process. Therefore, the natural process of collagen deposition by fibroblast is reduced. As a result, tissue fibrosis can be minimized to prevent macrophage and lymphocyte intervention in the wound site, reducing collagen deposition by fibroblasts. ${ }^{10}$ In the present case, although the trace of laser shots was clearly visible even 3 years after the procedure, clearly visible tissue fibrosis was not observed in the stromal layer with the slit-lamp examination with subsequent usage of topical steroid. As a result, good visual acuity was maintained. As regards postoperative endothelial cell densities, the rate of corneal endothelial cell loss was reported to range from $2.3 \%$ to $7 \%$ following $\mathrm{Nd}$ :YAG laser posterior capsulotomy. ${ }^{11}$ However, in the present case, it was $72.0 \%$ at 3 years after the operation. The mean energy required per individual laser shot for membranous-type PCO has been reported to be $1.8 \mathrm{~mJ}$, and the mean total energy required is reported to be 22.8 $\mathrm{mJ}{ }^{12}$ In our case, the mean energy per laser shot was 1.0 $\mathrm{mJ}$ and the total energy used was $14 \mathrm{~mJ}$. Thus, significant endothelial cell loss was most likely caused by the location of laser shots on the endothelium.

Although individual factors can influence the level of damage to the tissues, our case may indicate that while corneal transparency can be still maintained by misplaced laser shots of low energy levels, endothelial cells can be heavily damaged. Given the fact that there was no significant difference in CDE and endothelial cell density between the two eyes in the early postoperative period, the level of damage to the cataract operations to the endothelial cells in both eyes were most likely nearly identical. Bates et al reported 515 cells $/ \mathrm{mm}$ as the mean endothelial cell densities in bullous keratopathy and revealed that serial assessment of endothelial cell densities could be useful to predict the development of bullous keratopathy. ${ }^{13}$ Therefore, long-term observation is required after these complications. Although our case indicated that misplaced laser shots on the cornea may not be a vision-threatening complication, doctors should pay special attention to focus the laser accurately and avoid accidental shots to the cornea.

\section{Conclusion}

To the best of our knowledge, this is the first report of the $\mathrm{Nd}$ :YAG laser hitting the corneal layers during the treatment for PCO. This report implies the importance of the awareness of this rare complication and long term followup especially for monitoring the endothelial cell density. Furthermore, this case report indicated that topical steroid may be effective in minimizing tissue fibrosis, which corresponds to the biochemical theory.

\section{Acknowledgments}

We would like to thank Editage (www.editage.com) for English language editing.

\section{Disclosure}

The authors report no conflicts of interest in this work.

\section{References}

1. Wormstone IM. Posterior capsule opacification: a cell biological perspective. Exp Eye Res. 2002;74(3):337-347. doi:10.1006/exer.20 01.1153

2. Aron-Rosa D, Aron JJ, Griesemann M, Thyzel R. Use of the neodymium-YAG laser to open the posterior capsule after lens implant surgery: a preliminary report. $J$ Am Intraocul Implant Soc. 1980;6 (4):352-354. doi:10.1016/S0146-2776(80)80036-X

3. Karahan E, Er D, Kaynak S. An overview of Nd: YAGlaser capsulotomy. Med Hypothesis Discov Innov Ophthalmol. 2014;3 (2):45-50.

4. Ton Van C, Tran THC. Incidence of posterior capsular opacification requiring Nd: YAGcapsulotomy after cataract surgery and implantation of enVista MX60 IOL. J Fr Ophtalmol. 2018;41(10):899-903. doi:10.1016/j.jfo.2018.04.011

5. Johansson B. Glistenings, anterior/posterior capsular opacification and incidence of Nd: YAGlaser treatments with two aspheric hydrophobic acrylic intraocular lenses - A long-term intra-individual study. Acta Ophthalmol. 2017;95(7):671-677. doi:10.1111/aos.13444

6. Baratz KH, Cook BE, Hodge DO. Probability of Nd: YAGlaser capsulotomy after cataract surgery in Olmsted County, Minnesota. Am $J$ Ophthalmol. 2001;131(2):161-166. doi:10.1016/S0002-9394(00) 00795-9 
7. Burq MA, Taqui AM. Frequency of retinal detachment and other complications after neodymium: YAGLaser capsulotomy. $J$ Pak Med Assoc. 2008;58(10):550-552.

8. Chaudhry M, Baisakhiya S, Bhatia MS. A rare complication of Nd-YAG capsulotomy: propionibacterium acnes endophthalmitis. Nepal J Ophthalmol. 2011;3(1):80-82. doi:10.3126/nepjoph.v3i1. 4283

9. Vella M, Wickremasinghe S, Gupta N, Andreou P, Sinha A. YAG laser capsulotomy, an unusual complication. Eye (Lond). 2004;18 (2):193-194. doi:10.1038/sj.eye.6700548

10. Wilson SL, El Haj AJ, Yang Y. Control of scar tissue formation in the cornea: strategies in clinical and corneal tissue engineering. $J$ Funct Biomater. 2012;3(3):642-687. doi:10.3390/jfb3030642
11. Steinert FR Nd:YAGlaser posterior capsulotomy; 2013. American Academy of Ophthalmology. Available from: https://www.aao.org/ munnerlyn-laser-surgery-center/ndyag-laser-posterior-capsulotomy-3 . Accessed June 25, 2020.

12. Bhargava R, Kumar P, Prakash A, Chaudhary KP. Estimation of mean ND: YAG laser capsulotomy energy levels for membranous and fibrous posterior capsular opacification. Nepal J Ophthalmol. 2012;4(1):108-113. doi:10.3126/nepjoph.v4i1.5861

13. Bates AK, Cheng H, Hiorns RW. Pseudophakic bullous keratopathy: relationship with endothelial cell density and use of a predictive cell loss model. A preliminary report. Curr Eye Res. 1986;5(5):363-366. doi: $10.3109 / 02713688609025174$

\section{Publish your work in this journal}

The International Medical Case Reports Journal is an international, peer-reviewed open-access journal publishing original case reports from all medical specialties. Previously unpublished medical posters are also accepted relating to any area of clinical or preclinica science. Submissions should not normally exceed 2,000 words or 4 published pages including figures, diagrams and references. The manuscript management system is completely online and includes a very quick and fair peer-review system, which is all easy to use. Visit http://www.dovepress.com/testimonials.php to read real quotes from published authors. 